\title{
The Postglacial Rebound Signal of Fennoscandia Observed by Absolute Gravimetry, GPS, and Tide Gauges
}

\author{
Bjørn Ragnvald Pettersen \\ Department of Mathematical Sciences and Technology, Norwegian University of Life Sciences, P.O. Box 5003, \\ 1432 Ås, Norway \\ Correspondence should be addressed to Bjørn Ragnvald Pettersen, bjorn.pettersen@umb.no
}

Received 26 August 2010; Accepted 20 October 2010

Academic Editor: Petr Vaníček

Copyright ( $\odot 2011$ Bjørn Ragnvald Pettersen. This is an open access article distributed under the Creative Commons Attribution License, which permits unrestricted use, distribution, and reproduction in any medium, provided the original work is properly cited.

\begin{abstract}
We have compiled time derivatives of gravity and vertical motion for a dozen sites in Fennoscandia. Time series of absolute gravimetry and permanent GPS cover a time span of about a decade. Tide gauges have operated for many decades near seven of the sites. Linear relations are found to range from -0.17 to -0.22 for the slope between gravity and vertical uplift rates. An eustatic sea level rate of $1.2 \mathrm{~mm} /$ year is derived from these data. This compares well with results for North America and with theoretical predictions for viscoelastic Earth models.
\end{abstract}

\section{Introduction}

The postglacial movements of Fennoscandia have been monitored geometrically by terrestrial as well as space geodetic observing techniques. Vertical uplift rates relative to mean sea level have been derived to map the apparent uplift (e.g., [1]). Time series of permanent GPS-stations reveal both vertical and horizontal movements $[2,3]$. The geographical distribution of vertical uplift rates from these two independent sets of observations reveals an oval shaped uplift area with the major axis oriented towards northeast and maximum uplift in the northern part of the Gulf of Bothnia. The western perimeter of the uplift oval indicates a zero uplift line at or just outside the western coastline of Norway.

Investigations of gravity changes related to the postglacial uplift of Fennoscandia began in 1966 with relative gravimeters. Longitudinal land uplift gravity lines between $56^{\circ} \mathrm{N}$ and $65^{\circ} \mathrm{N}$ were established under the auspices of the Nordic Geodetic Commission. Observations are being collected episodically $[1,4]$. Several campaigns with absolute gravimeters were organized between 1976 and 1998. This effort became annual in 2003.

We have compiled GPS uplift rates for a dozen sites in Fennoscandia for which time series of absolute gravimetry also exists, spanning about a decade. Seven of these sites are located at the coast with nearby tide gauges having produced times series for the last 50-100 years.

\section{Data}

Gravity was first measured by absolute gravimeters in Fennoscandia in $1976[5,6]$. The number of observing sites increased in 1993 when two FG5-instruments [7] campaigned Finland, Norway, and Sweden. Episodic followup observations were made in 1995 and 1998 [8]. An ongoing observing program was initiated in 2003, employing several recently acquired FG5-instruments on an annual basis at more than three dozen sites throughout the Nordic countries [9]. Currently available data produce time series of absolute gravity observations for about a dozen sites covering a time span of a decade or more. They reveal that gravity decreases with time in Fennoscandia. The rates are large for sites in Finland and Sweden that are located near the maximum uplift region at the northern end of the Gulf of Bothnia. The rates decrease in all directions away from this region. Rates compiled from literature sources $[6,8,10]$ deviate no more than $0.3 \mu \mathrm{Gal} /$ year from each other. Eight of eleven sites in Table 1 show deviations less than $0.1 \mu \mathrm{Gal} /$ year. Rates and standard deviations listed in Table 1 (column 2) are from [10]. 
TABLE 1: Rates of gravity change $(\mu \mathrm{Gal} / \mathrm{yr})$ and geometric height change $(\mathrm{mm} / \mathrm{yr})$ in Fennoscandia.

\begin{tabular}{lccc}
\hline Site name & $\mathrm{d} g / \mathrm{d} t(\mathrm{AG})$ & $\mathrm{d} h / \mathrm{d} t(\mathrm{GPS})$ & $\mathrm{d} h / \mathrm{d} t(\mathrm{TG})$ \\
\hline Tromsø & $-0.2 \pm 0.3$ & $2.30 \pm 0.49$ & $0.05 \pm 0.48$ \\
Stavanger & $-0.1 \pm 0.3$ & $1.18 \pm 0.51$ & $-0.27 \pm 0.17$ \\
Trysil & $-1.1 \pm 0.1$ & 9.2 & \\
Onsala AN & $-0.8 \pm 0.1$ & $2.66 \pm 0.31$ & $1.42 \pm 0.23$ \\
Onsala AS & $-0.7 \pm 0.1$ & $2.66 \pm 0.31$ & $1.42 \pm 0.23$ \\
Mårtsbo & $-1.2 \pm 0.2$ & $6.74 \pm 0.15$ & $6.05 \pm 0.23$ \\
Skellefteå & $-1.8 \pm 0.2$ & $9.61 \pm 0.18$ & $8.54 \pm 0.30$ \\
Kiruna & $-0.8 \pm 0.4$ & $6.30 \pm 0.28$ & \\
Sodankylä & $-1.6 \pm 0.3$ & $7.12 \pm 0.31$ & \\
Vaasa AA & $-2.2 \pm 0.2$ & $8.62 \pm 0.19$ & $7.34 \pm 0.18$ \\
Vaasa AB & $-1.7 \pm 0.3$ & $8.62 \pm 0.19$ & $7.34 \pm 0.18$ \\
Metsähovi & $-0.5 \pm 0.2$ & $4.26 \pm 0.23$ & $2.44 \pm 0.17$ \\
Joensuu & $-1.7 \pm 0.8$ & $4.06 \pm 0.19$ & \\
\hline
\end{tabular}

Permanent GPS-stations have existed in Fennoscandia since 1991. National networks were subsequently established, now comprising several dozen stations in each country. Time series analysis allows vertical rates to be determined for many of these stations. Vertical rates compiled from literature sources $[11,12]$ deviate less than $0.6 \mathrm{~mm} /$ year from each other. Rates listed in Table 1 (column 3) are from [12], with the addition of Trysil from [13]. The uncertainty estimates of [12] are between \pm 0.2 and $\pm 0.5 \mathrm{~mm} /$ year for these stations.

Tide gauges have existed in Fennoscandia since 1774. The multinational cooperation of the "Mittel-Europäische Gradmessung" led to several tide gauges being established from 1880 onwards. Thus time series of 50-100 years exist for many coastal stations. Rates compiled from the PSMSL website (http://www.pol.ac.uk/psmsl/datainfo/rlr.trends) are listed in Table 1 (column 4).

\section{Results and Discussion}

The GPS-rates describe the land uplift of each station relative to the center of mass of the Earth. The observed sea level rates (including a eustatic rise of sea level) describe land uplift relative to the geoid. Following [1] we add an estimate of the geoid rise relative to the ellipsoid (i.e., $6 \%$ of the sea level rate) to obtain the absolute uplift. The sea level rate relative to the ellipsoid is thus $\dot{h}=\dot{H}_{\text {sealevel }}+\dot{N}$. A plot of $\dot{g}$ versus $\dot{h}$ (Figure 1), using data from Table 1, yields a linear regression of

$$
\dot{g}=-0.191( \pm 0.021) \cdot \dot{h}-0.236( \pm 0.085),
$$

with a correlation coefficient of $r=-0.94$. This line does not pass through the origin because the tide gauges contain the signal of eustatic sea level rise. At $\dot{g}=0$, the eustatic sea level is estimated as $0.236 / 0.191=1.2 \mathrm{~mm} / \mathrm{yr}$, identical to the value selected by [1].

A similar plot (Figure 2) may be produced using the GPSdata in Table 1. Linear regression yields

$$
\dot{g}=-0.165( \pm 0.040) \cdot \dot{h}-0.166( \pm 0.23)
$$

with a correlation coefficient of $r=-0.75$.

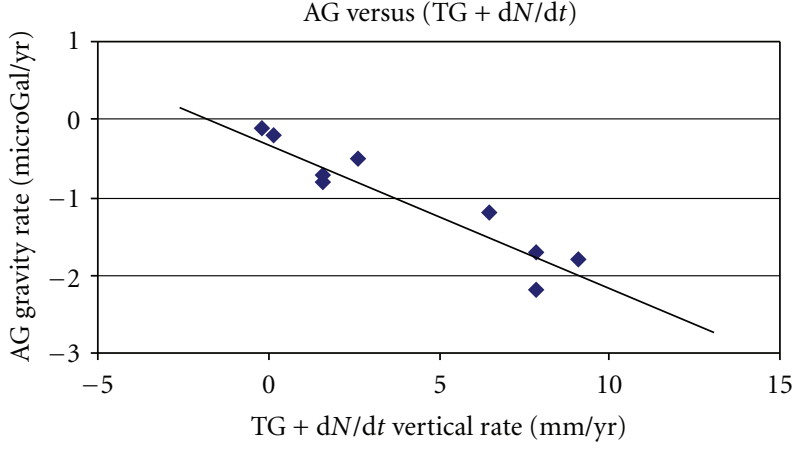

FIGURE 1: Linear regression between the gravity rate and the vertical uplift derived from tide gauges in Fennoscandia. See text for details.

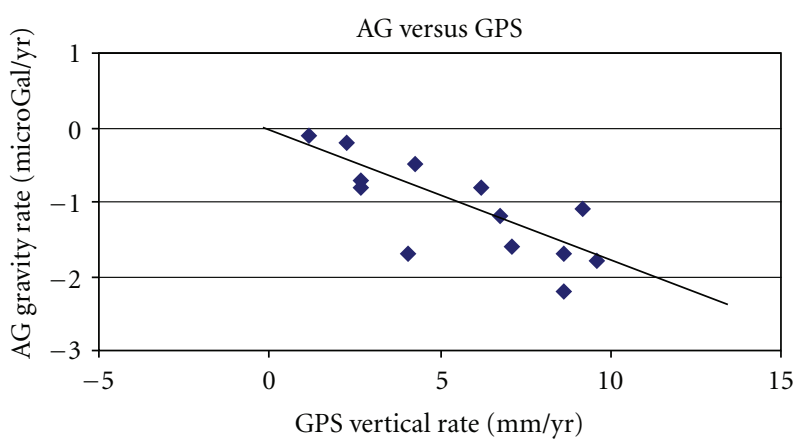

FIGURE 2: Linear regression between the gravity rate and the vertical uplift derived from permanent GPS in Fennoscandia.

We note that tide gauges produce a better regression than GPS. For a eustatic sea level rise of $1.2 \mathrm{~mm} /$ year, the regression lines from both tide gauges and GPS pass through the origin (within the errors) and have similar slope values (within errors). If only coastal stations (i.e., nine gravity stations with tide gauges in Table 1) are included in the regression analysis, the GPS-data yield

$$
\dot{g}=-0.217( \pm 0.025)+0.104( \pm 0.14)
$$

with an improved correlation coefficient of $r=-0.94$.

The ratio $\dot{g} / \dot{h}$ for Fennoscandia appears to be between -0.17 and $-0.22 \mu \mathrm{Gal} / \mathrm{mm}$. These values concur with those derived for a Bouguer plate with a mantle density of $3300 \mathrm{kgm}^{-3}$, namely, $\dot{g} / \dot{h}=-0.17 \mu \mathrm{Gal} / \mathrm{mm}$, rather than a free-air uplift of -0.31 . Our results also compare well with results derived from relative gravimetry in Fennoscandia by [1], updated by [4]. Gravity differences have been measured repeatedly from 1966 to 2003 for sites along the longitude at $63^{\circ} \mathrm{N}$. The difference between two sites on either side of the Fennoscandian uplift maximum has been derived. These sites are separated in longitude by $8^{\circ}-10^{\circ}$ and experience differences in vertical uplift of $5-7 \mathrm{~mm} / \mathrm{yr}$. The most recent update of analysis [4] lists $\dot{g} / \dot{h}$ values between -0.16 and $-0.20 \mu \mathrm{Gal} / \mathrm{mm}$.

Lambert et al. [14] compared gravity and GPS rates for 4 sites on the mid-North American continent and found a slope of $-0.18 \pm 0.03 \mu \mathrm{Gal} / \mathrm{mm}$. Their result required 
the correction of gravity values for a common interannual variation. This has not been applied to the Fennoscandian gravity data.

Numerical experiments by Wahr et al. with a viscoelastic earth model [15] produced an expected ratio of $-0.15 \mu \mathrm{Gal} / \mathrm{mm}$ for a wide range of viscosity profiles and lithosphere thicknesses. James and Ivins [16] arrived at similar results for the viscoelastic response of ICE-3G surface loads. Fang and Hager [17] showed that this numerical value is close to the Bouguer value because compressibility is practically absent in the viscoelastic response of a Maxwell Earth model. Several aspects of the elastic response are discussed in [18].

\section{Conclusions}

The gravity rates in Fennoscandia (as determined by absolute gravimetry) correlates linearly with the vertical uplift rates (as determined by GPS or tide gauge). For a eustatic sea level rise of $1.2 \mathrm{~mm} /$ year, the regression lines intercept the origin (within errors). The slopes are close to theoretical values by Wahr et al. [15] and James and Ivins [16], and to previous observational results by Mäkinen et al. [4] for Fennoscandia and Lambert et al. [14] for North America.

\section{Acknowledgments}

It is a pleasure to acknowledge discussions with Tony Lambert and Tom James during a visit to the Pacific Geoscience Centre, Sidney, BC, Canada in November 2006.

\section{References}

[1] M. Ekman and J. Mäkinen, "Recent postglacial rebound, gravity change and mantle flow in Fennoscandia," Geophysical Journal International, vol. 126, no. 1, pp. 229-234, 1996.

[2] G. A. Milne, J. L. Davis, J. X. Mitrovica et al., "Space-geodetic constraints on glacial isostatic adjustment in Fennoscandia," Science, vol. 291, no. 5512, pp. 2381-2385, 2001.

[3] H.-G. Scherneck, J. M. Johansson, H. Koivula, T. van Dam, and J. L. Davis, "Vertical crustal motion observed in the BIFROST project," Journal of Geodynamics, vol. 35, no. 4-5, pp. 425-441, 2003.

[4] J. Mäkinen, A. Engfeldt, B. G. Harsson et al., "The Fennoscandian land uplift gravity lines 1966-2003," in Gravity, Geoid and Space Missions, C. Jekeli, L. Bastos, and J. Fernandes, Eds., IAG Symposium 129, pp. 328-332, Springer, Berlin, Germany, 2005.

[5] L. Cannizzo, G. Cerutti, and I. Marson, "Absolute-gravity measurements in Europe," Il Nuovo Cimento C, vol. 1, no. 1, pp. 39-85, 1978.

[6] J. Mäkinen, M. Bilker-Koivula, F. Klopping, R. Falk, L. Timmen, and O. Gitlein, "Time series of absolute gravity in Finland," in Proceedings of the 1st International Symposium of the International Gravity Field Service, Istanbul, Turkey, August-September 2006.

[7] T. M. Niebauer, G. S. Sasagawa, J. E. Faller, R. Hilt, and F. Klopping, "A new generation of absolute gravimeters," Metrologia, vol. 32, no. 3, pp. 159-180, 1995.
[8] H. Wilmes, R. Falk, F. Klopping et al., "Long-term gravity variations in Scandinavia from repeated absolute gravity measurements in the period 1991 to 2003," in Proceedings of the IAG International Symposium on Gravity, Geoid, and Space Missions (GGSM '04), IAG Symposium 129, 2004, CD.

[9] L. Timmen, O. Gitlein, J. Müller et al., "Observing Fennoscandian gravity change by absolute gravimetry," in Geodetic Deformation Monitoring: From Geophysical to Engineering Roles, IAG Symposium 131, pp. 193-199, Springer, London, UK, 2006.

[10] A. Engfeldt, L. Timmen, O. Gitlein et al., "Observing absolute gravity acceleration in the Fennoscandian Land Uplift Area," in Proceedings of the 1st International Symposium of the International Gravity Field Service, Istanbul, Turkey, AugustSeptember 2006.

[11] K. Kaniuth and S. Vetter, "Vertical velocities of European coastal sites derived from continuous GPS observations," GPS Solutions, vol. 9, no. 1, pp. 32-40, 2005.

[12] M. Lidberg, J. M. Johansson, H.-G. Scherneck, and J. L. Davis, "An improved and extended GPS-derived 3D velocity field of the glacial isostatic adjustment (GIA) in Fennoscandia," Journal of Geodesy, vol. 81, no. 3, pp. 213-230, 2007.

[13] O. Kristiansen, personal communication, November 2005.

[14] A. Lambert, N. Courtier, and T. S. James, "Long-term monitoring by absolute gravimetry: tides to postglacial rebound," Journal of Geodynamics, vol. 41, no. 1-3, pp. 307-317, 2006.

[15] J. Wahr, D. Han, and A. Trupin, "Predictions of vertical uplift caused by changing polar ice volumes on a viscoelastic earth," Geophysical Research Letters, vol. 22, no. 8, pp. 977-980, 1995.

[16] T. S. James and E. R. Ivins, "Predictions of Antarctic crustal motions driven by present-day ice sheet evolution and by isostatic memory of the Last Glacial Maximum," Journal of Geophysical Research B, vol. 103, no. 3, pp. 4993-5017, 1998.

[17] M. Fang and B. H. Hager, "Vertical deformation and absolute gravity," Geophysical Journal International, vol. 146, no. 2, pp. 539-548, 2001.

[18] C. de Linage, J. Hinderer, and Y. Rogister, "A search for the ratio between gravity variation and vertical displacement due to a surface load," Geophysical Journal International, vol. 171, no. 3, pp. 986-994, 2007. 

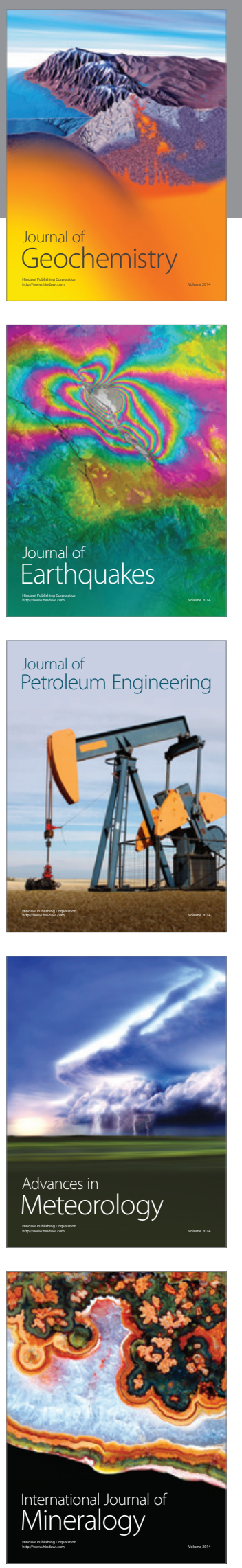
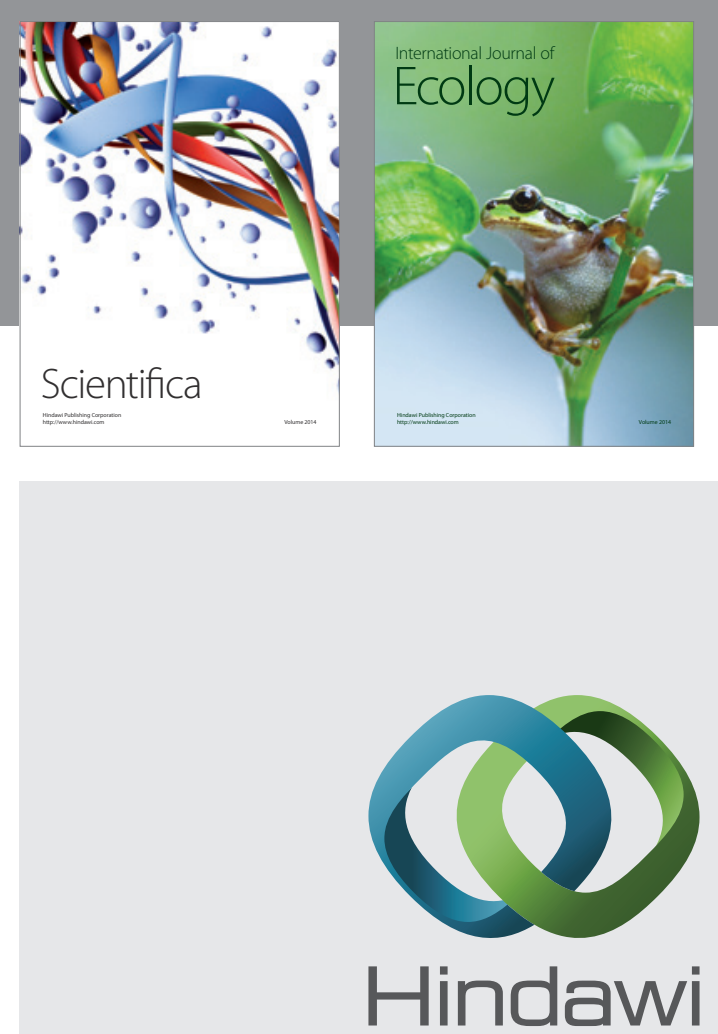

Submit your manuscripts at http://www.hindawi.com
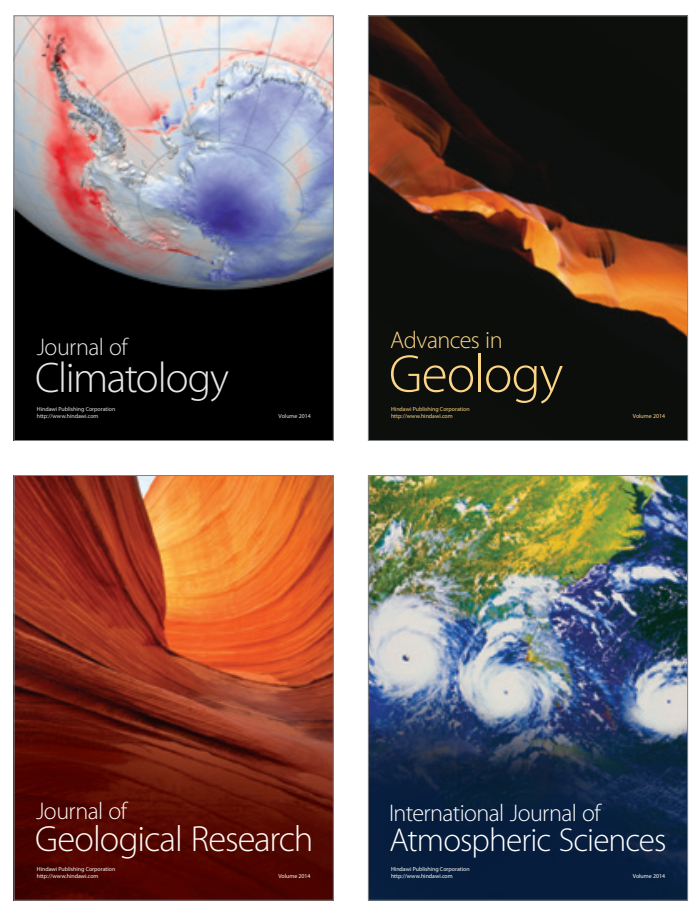
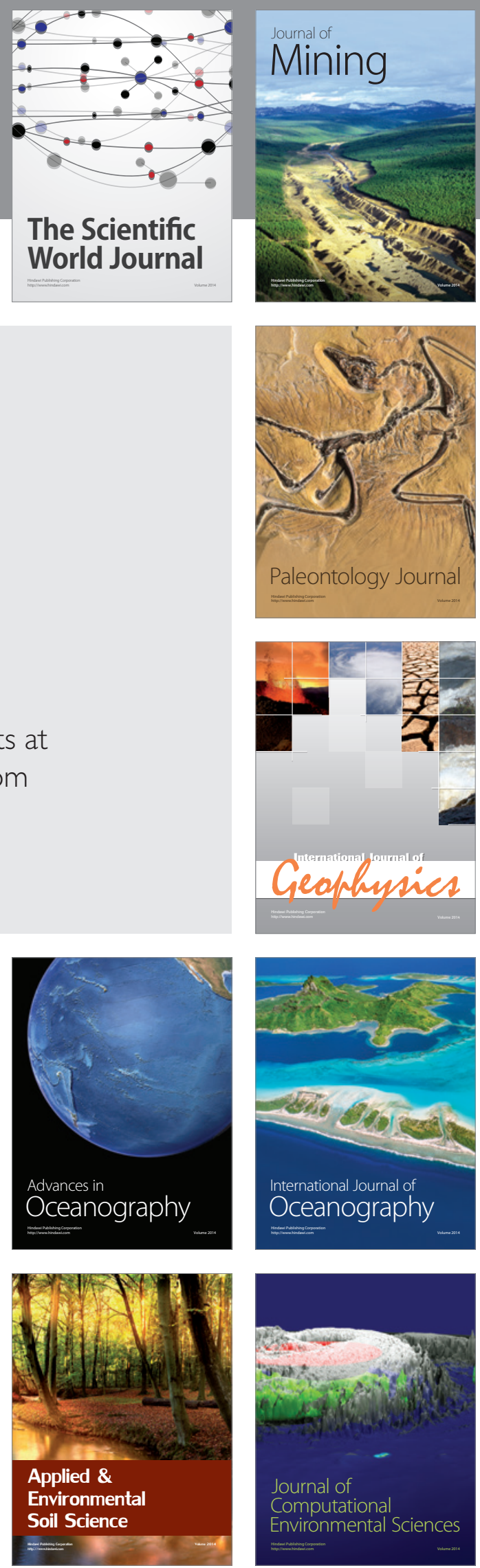